\title{
Influence of pain severity on the quality of life in patients with head and neck cancer before antineoplastic therapy
}

Karine G Oliveira ${ }^{1 \dagger}$, Sandra V von Zeidler ${ }^{2 \dagger}$, Jose RV Podestá ${ }^{3 \dagger}$, Agenor Sena ${ }^{3+}$, Evandro D Souza ${ }^{3 \dagger}$, Jeferson Lenzi ${ }^{3 \dagger}$, Nazaré S Bissoli ${ }^{1 \dagger}$ and Sonia A Gouvea ${ }^{1 *}$

\begin{abstract}
Background: The aim of this study was to assess the severity of pain and its impact on the quality of life (QoL) in untreated patients with head and neck squamous cell carcinoma (HNSCC).

Methods: A study group of 127 patients with HNSCC were interviewed before antineoplastic treatment. The severity of pain was measured using the Brief Pain Inventory (BPI) questionnaire, and the QoL was assessed with the European Organization for Research and Treatment of Cancer Quality of Life Questionnaire Core-30 (EORTC QLQ-C30) and the head and neck module (QLQ-H\&N35).

Results: The mean age of the patients was 57.9 years, and there was a predominance of men (87.4\%). The most frequent site of the primary tumor was the oral cavity $(70.6 \%)$, and the majority of the patients had advanced cancers (stages III and IV). QoL in early stage of cancer obtained better scores. Conversely, the patients with advanced stage cancer scored significantly higher on the symptom scales regarding fatigue, pain, appetite loss and financial difficulties, indicating greater difficulties. Regard to the severity of pain, patients with moderate-severe pain revealed a significantly worse score than patients without pain.

Conclusions: The severity of pain is statistically related to the advanced stages of cancer and directly affects the QoL. An assessment of the quality of life and symptoms before therapy can direct attention to the most important symptoms, and appropriate interventions can then be directed toward improving QoL outcomes and the response to treatment.
\end{abstract}

\section{Background}

Head and neck cancer (HNC) comprises a group of tumors that arise in the oral cavity, pharynx and larynx. It is the $6^{\text {th }}$ most common cancer worldwide, accounting for $6 \%$ of cancer cases. Approximately $40 \%$ of these tumors occur in the oral cavity, $15 \%$ occur in the pharynx, and $25 \%$ occur in the larynx; in $90 \%$ of the cases, the most common histologic type is squamous cell carcinoma $[1,2]$.

Pain is one of the several symptoms of cancer that create a poor quality of life (QoL) because pain affects physical functions and has an emotional impact [3-5]. In HNC,

\footnotetext{
*Correspondence: gouveasa@yahoo.com.br

'Equal contributors

'Department of Physiological Sciences, Health Sciences Center, Federal University of Espirito Santo, Vitória, Brazil

Full list of author information is available at the end of the article
}

pain affects the oral functions and is a complaint in approximately $58 \%$ of the patients awaiting treatment and in $30 \%$ of the treated patients $[4,6]$. In a meta-analysis of 52 studies that calculated the prevalence of cancer pain, head and neck cancer had the highest prevalence of pain, surpassing gynecological, gastrointestinal, lung and breast tumors [7].

The complaint of pain has been reported in all clinical stages of oral cancer, with $88.1 \%$ of the cases occurring in stages III-IV. Some studies have shown a correlation between pain and tumor staging, with pain being the initial symptom in approximately $20 \%$ of the patients with oral squamous cell carcinoma $[5,6]$.

Cancer pain is multidimensional and is directly associated with QoL [8]. The assessment of QoL has increasingly moved toward a modular approach, which allows for the evaluation of multiple dimensions of functioning. A

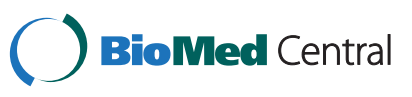


general module, which assesses the symptoms commonly experienced by cancer patients, is supplemented by a siteor treatment-specific module that assesses difficulties unique to that particular type of cancer or treatment. Studies have confirmed that both general and site-specific measures contribute to obtaining important information concerning QoL [9].

For cancer patients, pain and symptom control are the best predictors of overall QoL scores because the effects of unrelieved pain and poorly managed symptoms have been shown to interfere with the activities of daily living, mood, mobility, and independence. Therefore, when the control of symptoms is not attended to, the QoL tends to be reduced $[8,10]$. Additionally, studies on the intensity of pain and QoL among patients with HNC before treatment are lacking.

We hypothesized that patients with $\mathrm{HNC}$ who experienced moderate to severe pain before antineoplastic treatment would report more interference with QoL scores than those patients without pain. Therefore, the purpose of this study was to assess pain severity and its impact on the QoL in untreated patients with head and neck squamous cell carcinoma (HNSCC), and assess QoL of these patients with respect to pain severity, clinical stage of the primary tumor, and lymph nodes involvement.

\section{Methods}

\section{Patients}

This study is prospective and controlled and it was approved by the Research Ethics Committee of the Espirito Santo Federal University (Protocol n ${ }^{\circ} 99.242 / 2012$ ). We interviewed 127 outpatients with primary head and neck squamous cell carcinoma consecutively who had undergone medical examinations in 2012 at the Santa Rita de Cassia Hospital-AFECC, Vitoria, ES, Brazil. The cancer patients were distributed into groups with no pain $(\mathrm{N}=52)$, mild pain $(\mathrm{N}=47)$, and moderate to severe pain $(\mathrm{N}=28)$. Inclusion criteria were patients with untreated HNSCC aged over 18 years and both gender. The exclusion criteria were patients who had already been treated for HNSCC, had recurrent malignant disease, were unable to speak Portuguese or had a functional status sufficiently impaired to prevent answering the questionnaires. Clinical data (gender, age, tobacco and alcohol consumption, tumor location and tumor stage) were obtained from medical records.

\section{Assessments}

The pain was measured using the item of "average pain" during the last 24 hours in the Brief Pain Inventory (BPI) [11], which was validated in the Brazilian population [12]. The pain scores were categorized into three groups according to the BPI average pain: no pain (0), mild pain (1-4), and moderate (5-6) to severe (7-10) pain [13].
The BPI asks patients to rate their pain intensity and pain interference (with general activities, mood, walking ability, normal work, relationship with others, sleep, and enjoyment of life) on an 11-point scale ranging from 0 (no pain/no interference) to 10 (as bad as you can imagine/ complete interference) [11].

The QoL was assessed with the European Organization for Research and Treatment of Cancer Quality of Life Questionnaire Core-30 (EORTC QLQ-C30) version 3.0 [14], which was validated in the Brazilian population [15].

This is a 30-item questionnaire that consists of 5 functional scales (physical, role, cognitive, emotional, and social functioning), 3 symptom scales (fatigue, pain, and nausea and vomiting), a global health status/QoL scale, and a number of single items assessing additional symptoms commonly reported by patients with cancer (dyspnea, loss of appetite, insomnia, constipation, diarrhea, and financial difficulties). The patients were asked to rate each item on a 4-point scale and the global health status/QoL scale item on a 7-point scale [16].

The Quality of Life Questionnaire Head and Neck Cancer Module (EORTC QLQ-H\&N35) [17] has 35 specific questions concerning problems attributed to $\mathrm{HNC}$ and its treatment-related side effects. There are 7 scaled answers for pain, swallowing, sensibility, speech, eating in a social setting, social contact, and sexuality. In addition, 11 individual topics were evaluated taking into account the anatomic site, symptoms, and treatment (dental problems, mouth opening, dry mouth, poor salivation, coughing, sense of illness, analgesic use, nutrition difficulties, gastric tube, and weight loss or gain) [17].

All scales and single items were linearly transformed to provide a score ranging from 0 to 100; a high score on the functional scale and for global quality of life (QoL) was representative of a high level of functioning and a high QoL. However, a high score on the symptom scale represented a high level of symptomatology and problems [18]. The instruments were filled by patients with staff assistance.

\section{Statistical analyses}

The scores from the EORTC QLQ-C30 and EORTC QLQ-H\&N35 were interpreted according to the EORTC scoring manual [18]. Internal consistency in the questions was determined using Cronbach's $\alpha$ coefficient, which is used as an indicator of scale reliability. The distribution of quantitative variables was determined using the mean and standard deviation (determined as normal or abnormal using the Kolmogorov-Smirnov test). An association between the domains and other factors were examined using nonparametric tests (Mann-Whitney and Kruskal-Wallis tests). Qualitative variables were analyzed using the Chi square test or Fisher's exact test. The statistical software program SPSS version 17 for Windows (Statistical Package 
for the Social Sciences, Chicago, USA) was used for the data analysis. The level of statistical significance was accepted at $p<0.05$.

\section{Results}

The main features of our series of 127 patients with HNSCC are summarized in Table 1. The mean age of the patients was 57.9 years (range, 21-89), and there was predominance of men (87.4\%). The most frequent site of the primary tumor was the oral cavity (70.6\%),

Table 1 Clinical and epidemiological features $(n=127)$

\begin{tabular}{|c|c|}
\hline Age (years) & \\
\hline Range & $21-89$ \\
\hline \multirow[t]{2}{*}{ Mean (SD) } & $57.9(12.3)$ \\
\hline & n (\%) \\
\hline \multicolumn{2}{|l|}{ Gender } \\
\hline Female & $16(12.6)$ \\
\hline Male & $111(87.4)$ \\
\hline \multicolumn{2}{|l|}{ Currently smoking } \\
\hline Yes & $83(65.4)$ \\
\hline No & $44(34.6)$ \\
\hline \multicolumn{2}{|l|}{ Alcohol } \\
\hline Yes & $78(61.4)$ \\
\hline No & $49(38.6)$ \\
\hline \multicolumn{2}{|l|}{ Education } \\
\hline High school or less & $98(77.2)$ \\
\hline College or more & $29(22.8)$ \\
\hline \multicolumn{2}{|c|}{ Primary tumor location } \\
\hline Oral cavity & $77(60.6)$ \\
\hline Oropharynx & $28(22.1)$ \\
\hline Hypopharynx & $4(3.1)$ \\
\hline Larynx & $18(14.2)$ \\
\hline \multicolumn{2}{|l|}{ TNM stage } \\
\hline । & $25(19.6)$ \\
\hline$\|$ & $19(15)$ \\
\hline III & $26(20.5)$ \\
\hline IV & $57(44.9)$ \\
\hline \multicolumn{2}{|l|}{$\mathbf{T}$} \\
\hline 1 & $25(19.7)$ \\
\hline 2 & $30(23.6)$ \\
\hline 3 & $24(18.9)$ \\
\hline 4 & $48(37.8)$ \\
\hline \multicolumn{2}{|l|}{$\mathbf{N}$} \\
\hline+ & $84(66.1)$ \\
\hline 0 & $43(33.9)$ \\
\hline
\end{tabular}

Abbreviations: $T$, Tumor size; $N$, Lymph node involvement. and the majority of the patients had advanced cancers (stages III and IV).

The reliability coefficients (Cronbach's $\alpha$ ), means, and SDs for the EORTC QLQ-C30 scales are listed in Table 2. The reliability coefficient for most of the scales ranged from 0.73 to 0.89 , indicating satisfactory internal consistency, while nausea/vomiting (NV) had a moderate coefficient alpha of 0.67 . Only the cognitive functioning scale (CF) presented a lower coefficient (0.31). Reliability coefficients, means, and SDs for the EORTC QLQ-H\&N35 are listed in Table 3. Each of the scales demonstrated a high $\alpha$ coefficient $(>0.70)$, except for the speech scale (HNSP) and the social contact scale (HNSC), both of which had coefficients equal to 0.68 , which is considered moderate.

The reliability of the BPI was evaluated according to the internal consistency (Cronbach's $\alpha$ coefficient). The mean score of item "average pain" during the last 24 hours in the BPI was 4.1. We separately calculated alpha coefficients for pain severity and pain interference. The internal consistency of the pain severity dimension was 0.82 and for the pain interference dimension was 0.92 , indicating a satisfactory internal validity $(>0.70)$.

The comparison of the EORTC QLQ-C30 scales with the tumor size $(\mathrm{T})$ and lymph node involvement $(\mathrm{N})$ indicated that the patients with an early stage tumor scored significantly higher in physical functioning ( $\mathrm{T}, p=0.025$; $\mathrm{N}, p=0.024$ ), role functioning ( $\mathrm{T}, p=0.010 ; \mathrm{N}, p=0.004$ ) and social functioning ( $\mathrm{T}, p=0,035 ; \mathrm{N}, p=0.002$ ), indicating better functioning. Conversely, the patients with an advanced-stage tumor scored significantly higher on the

Table 2 Descriptive analyses of the EORT QLQ-C30 items and reliability analysis

\begin{tabular}{lcc}
\hline QLQ-C30 & Mean(SD) & Cronbach's a \\
\hline Global quality of life/QoL & $65.8(27.1)$ & 0.81
\end{tabular}

Functional scales

$\begin{array}{lll}\text { Physical functioning } & 80.2(23.3) & 0.73\end{array}$

$\begin{array}{lll}\text { Role functioning } & 80.7(32.3) & 0.78\end{array}$

Emotional functioning $\quad 64.5(33.5) \quad 0.85$

$\begin{array}{lll}\text { Cognitive functioning } & 82.1(25.0) & 0.31\end{array}$

$\begin{array}{lll}\text { Social functioning } & 89.8(23.7) & 0.70\end{array}$

Symptom scales

$\begin{array}{lll}\text { Fatigue } & 21.7(28.3) & 0.75\end{array}$

Nausea and vomiting $\quad 5.5(15.7) \quad 0.67$

$\begin{array}{lll}\text { Pain } & 36.1(38.1) & 0.89\end{array}$

Dyspnea $\quad 9.1(23.6)$

Insomnia $\quad 36.7$ (42.7)

Appetite loss $\quad 31.4(40.3)$

Constipation 23.8 (38.9)

Diarrhea $2.1(11.6)$

Financial difficulties $\quad 30.7(42.9)$ 
Table 3 Descriptive analyses of the EORT QLQ-H\&N35 items and reliability analysis

\begin{tabular}{lcc}
\hline QLQ-H\&N35 & Mean (SD) & Cronbach's a \\
\hline Pain & $30.5(31.0)$ & 0.78 \\
Swallowing & $32.3(34.0)$ & 0.86 \\
Senses problems & $15.8(30.7)$ & 0.85 \\
Speech problems & $23.8(29.6)$ & 0.68 \\
Trouble with social eating & $22.6(28.6)$ & 0.81 \\
Trouble with social contact & $11.6(17.5)$ & 0.68 \\
Less sexuality & $23.2(36.5)$ & 0.98 \\
Teeth & $18.1(35.1)$ & - \\
Opening mouth & $19.9(35.2)$ & - \\
Dry mouth & $22.0(36.1)$ & - \\
Sticky saliva & $41.7(43.4)$ & - \\
Coughing & $23.1(29.2)$ & - \\
Felt ill & $19.1(34.7)$ & - \\
Pain killers & $66.9(47.2)$ & - \\
Nutritional supplements & $5.5(22.9)$ & - \\
Feeding tube & 0 & - \\
Weight loss & $47.2(50.1)$ & \\
Weight gain & $14.9(35.8)$ & \\
\hline
\end{tabular}

Table 4 EORTC QLQ-C30 scales and TN stage

\begin{tabular}{|c|c|c|c|c|c|c|c|c|}
\hline \multirow[b]{3}{*}{ EORTC QLQ-C30 } & \multicolumn{4}{|c|}{$T^{*}$} & & \multicolumn{2}{|c|}{$\mathrm{N}^{* *}$} & \multirow[b]{3}{*}{$p$} \\
\hline & $\begin{array}{c}\text { T1 } \\
(\mathrm{n}=25)\end{array}$ & $\begin{array}{c}\text { T2 } \\
(\mathrm{n}=30)\end{array}$ & $\begin{array}{c}\text { T3 } \\
(\mathrm{n}=24)\end{array}$ & $\begin{array}{c}\text { T4 } \\
(\mathrm{n}=48)\end{array}$ & & $\begin{array}{c}\text { No } \\
(\mathrm{n}=43)\end{array}$ & $\begin{array}{c}\mathrm{N}+ \\
(\mathrm{n}=84)\end{array}$ & \\
\hline & Mean (SD) & Mean (SD) & & Mean (SD) & $p$ & & & \\
\hline Emotional functioning & $75.6(27.9)$ & $70.8(34.1)$ & $53.8(35.8)$ & $60.0(33.0)$ & 0.085 & $69.5(31.0)$ & $54.6(36.2)$ & 0.039 \\
\hline Physical functioning & $90.4(17.2)$ & $84.6(17.6)$ & $75.2(25.5)$ & $74.5(26.1)$ & 0.025 & $83.8(21.0)$ & $73.1(26.1)$ & 0.024 \\
\hline Role functioning & $97.3(13.3)$ & $79.4(34.3)$ & $77.7(36.3)$ & $74.3(33.8)$ & 0.010 & $86.3(27.2)$ & $69.7(38.5)$ & 0.004 \\
\hline Cognitive functioning & $82.6(22.8)$ & $85.5(18.9)$ & $79.1(28.7)$ & $81.2(27.8)$ & 0.938 & $84.1(24.1)$ & $78.2(26.6)$ & 0.158 \\
\hline Social functioning & $98.6(6.6)$ & $91.1(22.6)$ & $83.3(23.0)$ & $87.8(29.1)$ & 0.035 & $94.0(19.4)$ & $81.7(29.0)$ & 0.002 \\
\hline Global quality of life/QoL & $75.6(19.1)$ & $69.7(26.5)$ & 60.7 (33.6) & $60.9(26.4)$ & 0.130 & $70.3(23.4)$ & $57.1(31.6)$ & 0.033 \\
\hline Fatigue & $9.3(16.8)$ & $15.1(22.3)$ & $25.4(30.1)$ & $30.5(32.6)$ & 0.012 & $16.9(26.5)$ & $31.2(29.7)$ & 0.003 \\
\hline Nausea and Vomiting & $3.3(10.7)$ & $3.3(9.1)$ & $11.8(24.8)$ & $4.8(14.9)$ & 0.252 & $3.9(13.1)$ & $8.5(19.7)$ & 0.090 \\
\hline Pain & $8.0(16.0)$ & $33.8(34.3)$ & $45.8(44.0)$ & $47.2(38.4)$ & $<0.001$ & $27.5(34.3)$ & $52.7(39.8)$ & 0.001 \\
\hline Dyspnea & $5.3(12.4)$ & $6.6(22.1)$ & $19.4(33.9)$ & $7.6(22.0)$ & 0.124 & $9.1(23.9)$ & $9.3(23.3)$ & 0.816 \\
\hline Insomnia & $25.3(36.3)$ & $32.2(39.6)$ & $30.5(43.8)$ & $48.6(45.5)$ & 0.129 & $30.5(39.4)$ & $48.8(46.7)$ & 0.041 \\
\hline Appetite loss & $17.3(33.4)$ & $24.4(40.9)$ & $38.8(41.3)$ & $39.5(41.0)$ & 0.041 & $25.3(38.5)$ & $43.4(41.4)$ & 0.010 \\
\hline Constipation & $9.3(29.0)$ & $25.5(38,8)$ & $33.3(43.9)$ & $25.6(40.2)$ & 0.127 & $20.2(36.2)$ & $31.0(43.2)$ & 0.135 \\
\hline Diarrhea & 0 & $1.1(6.0)$ & $5.5(21.2)$ & $2.0(10.6)$ & 0.511 & $0.7(5.1)$ & 4.6 (18.6) & 0.199 \\
\hline Financial difficulties & $12.0(27.0)$ & $24.4(40.9)$ & $45.8(48.9)$ & $36.8(44.6)$ & 0.039 & $22.6(38.0)$ & $46.5(47.7)$ & 0.006 \\
\hline
\end{tabular}

*Kruskal-Wallis test, **Mann Whitney test. Abbreviations: T, Tumor size; $N$, Lymph node involvement. symptom scales with regard to fatigue (T, $p=0.012 ; \mathrm{N}$, $p=0.003$ ), pain ( $\mathrm{T}, p<0.001 ; \mathrm{N}, p=0.001$ ), appetite loss (T, $p=0.041 ; \mathrm{N}, p=0.010$ ) and financial difficulties ( $\mathrm{T}$, $p=0.039 ; \mathrm{N}, p=0.006$ ), indicating greater difficulties (Table 4). On the EORTC QLQ-H\&N35 scales, the patients with advanced-stage tumors had significantly higher scores on pain (T, $p<0.001 ; \mathrm{N}, p<0.001$ ), swallowing ( $\mathrm{T}, p<0.001 ; \mathrm{N}, p<0.001)$, social eating ( $\mathrm{T}, p<0.001$; , $P<0.001$ ), social contact (T, $p=0.005 ; \mathrm{N}, p<0.001$ ), teeth (T, $p=0.046 ; \mathrm{N}, p=0.001$ ), sticky saliva (T, $p<0.001 ; \mathrm{N}$, $p=0.024$ ), pain killers (T, $p<0.001 ; \mathrm{N}, p=0.038)$ and weight loss (T, $p<0.001 ; \mathrm{N}, p<0.001$ ), indicating greater impairment (Table 5).

Significant differences in the EORTC scales were found with regard to pain intensity. On the EORTC QLQ-C30, the cancer group without pain had better scores on all of the functional scales: physical functioning ( $\mathrm{PF}, p<0.001$ ), role functioning (RF, $p<0.001$ ), emotional functioning (EF, $p=0.002)$, cognitive functioning (CF, $p=0.027$ ), social functioning (SF, $p=0.002$ ) and global quality of life $(\mathrm{QL}, p<0.001$ ) (Figure 1A). However, with regard to the symptom scales, the cancer group with moderate-severe pain indicated greater impairment on the fatigue (FA, $p<0.001$ ), insomnia (SL, $p<0.001$ ), appetite loss (AP, $p=0.001)$ and constipation (CO, $p<0.001)$ scales (Figure 1B). The cancer group with mild pain showed greater impairment on the nausea/vomiting (NV, $p=0.045)$ and financial difficulties (FI, $p<0.001$ ) scales when compared with the cancer group with no pain. 
Table 5 EORTC QLQ-H\&N35 scales and TN stage

\begin{tabular}{|c|c|c|c|c|c|c|c|c|}
\hline \multirow[b]{2}{*}{ EORTC QLQ -H\&N35 } & \multicolumn{4}{|c|}{$\mathrm{T}^{*}$} & & \multicolumn{2}{|c|}{$\mathrm{N}^{* *}$} & \multirow[b]{2}{*}{$p$} \\
\hline & $\begin{array}{c}\text { T1 } \\
(\mathrm{n}=25) \\
\text { Mean (SD) }\end{array}$ & $\begin{array}{c}\text { T2 } \\
(\mathrm{n}=30) \\
\text { Mean (SD) }\end{array}$ & $\begin{array}{c}\text { T3 } \\
(n=24) \\
\text { Mean (SD) }\end{array}$ & $\begin{array}{c}\text { T4 } \\
(n=48) \\
\text { Mean (SD) }\end{array}$ & $p$ & $\begin{array}{c}\text { N0 } \\
(n=43) \\
\text { Mean (SD) }\end{array}$ & $\begin{array}{c}\mathrm{N}+ \\
(\mathrm{n}=84) \\
\text { Mean (SD) }\end{array}$ & \\
\hline Pain & $7.6(13.5)$ & $29.4(26.5)$ & $28.4(28.2)$ & $44.2(34.5)$ & $<0.001$ & $24.0(29.2)$ & $43.4(30.7)$ & $<0.001$ \\
\hline Swallowing & $2.0(6.0)$ & $32.7(32.8)$ & $31.2(33.5)$ & $48.4(33.3)$ & $<0.001$ & $22.8(32.0)$ & $50.9(30.1)$ & $<0.001$ \\
\hline Senses problems & $15.3(33.6)$ & $10.0(21.2)$ & $16.6(28.2)$ & $19(35.4)$ & 0.926 & $14.6(30,6)$ & $18.2(31.2)$ & 0.362 \\
\hline Speech problems & $13.7(25.7)$ & $15.1(22.5)$ & $30.5(33.4)$ & $31.2(31.2)$ & 0.029 & $20.8(27.9)$ & $29.7(32.2)$ & 0.240 \\
\hline Trouble with social eating & $2.0(6.9)$ & $19.1(26.6)$ & $25.6(29.8)$ & $34.0(30.5)$ & $<0.001$ & $14.4(23.5)$ & $38.5(31.2)$ & $<0.001$ \\
\hline Trouble with social contact & $5.0(7.2)$ & $7.7(14.0)$ & $18.8(20.4)$ & $13.8(20.1)$ & 0.005 & $7.4(10.7)$ & $19.8(24.2)$ & 0.001 \\
\hline Less sexuality & $12.0(25.2)$ & $16.1(29.1)$ & $29.1(43.1)$ & $30.5(40.5)$ & 0.211 & $14.0(29.1)$ & $41.0(42.9)$ & $<0.001$ \\
\hline Teeth & $4.0(14.6)$ & $16.6(34.7)$ & $12.5(29.1)$ & $29.1(42.1)$ & 0.046 & $10.3(26.8)$ & $33.3(43.6)$ & 0.001 \\
\hline Opening mouth & $1.3(6.6)$ & $10.0(27.8)$ & $19.4(30.9)$ & $36.1(42.8)$ & $<0.001$ & $15.4(30.3)$ & $28.6(42.1)$ & 0.112 \\
\hline Dry mouth & $25.3(38.8)$ & $27.7(37.2)$ & $18.0(36.7)$ & $18.7(34.3)$ & 0.416 & $22.2(36.7)$ & $21.7(35.5)$ & 0.946 \\
\hline Sticky saliva & $13.3(27.2)$ & $37.7(40.8)$ & $34.7(45.5)$ & $62.5(41.6)$ & $<0.001$ & $35.3(40.5)$ & $54.2(46.5)$ & 0.024 \\
\hline Coughing & $20.0(25.4)$ & $26.6(33.2)$ & $22.2(27.2)$ & $22.9(30.0)$ & 0.955 & $21.4(28.6)$ & $26.3(30.4)$ & 0.337 \\
\hline Felt ill & $8.0(19.9)$ & $11.1(26.7)$ & $23.6(38.6)$ & $27.7(40.8)$ & 0.125 & $13.8(29.3)$ & $29.4(41.9)$ & 0.042 \\
\hline Pain killers & $28.0(45.8)$ & $70.0(46.6)$ & $83.3(38.0)$ & $77.0(42.4)$ & $<0.001$ & $60.7(49.1)$ & $79.0(41.1)$ & 0.038 \\
\hline Nutritional supplements & $8.0(27.6)$ & $6.6(25.3)$ & 0 & $6.2(24.4)$ & 0.613 & $4.7(21.4)$ & $6.9(25.7)$ & 0.606 \\
\hline Feeding tube & 0 & 0 & 0 & 0 & - & 0 & 0 & - \\
\hline Weight loss & $4.0(20.0)$ & $40.0(49.8)$ & $54.1(50.8)$ & $70.8(45.9)$ & $<0.001$ & $34.5(47.8)$ & $72.0(45.3)$ & $<0.001$ \\
\hline Weight gain & $28.0(45.8)$ & $23.3(43.0)$ & $8.3(28.2)$ & $6.2(24.4)$ & 0.035 & $16.6(37.4)$ & $11.6(32.4)$ & 0.453 \\
\hline
\end{tabular}

*Kruskal-Wallis test, ${ }^{*}$ Mann Whitney test. Abbreviations: $T$, Tumor size; $N$, Lymph node involvement.

The EORTC QLQ-H\&N35 questionnaire also demonstrated significantly worse scores on the swallowing (HNSW, $p<0.001$ ), speech problems (HNSP, $p<0.001$ ), social eating (HNSO, $p<0.001$ ), social contact (HNSC, $p<0.001$ ), teeth (HNTE, $p=0.016$ ), opening mouth (HNOM, $p=0.001$ ), dry mouth (HNDR, $p=0.004$ ), sticky saliva (HNSS, $p<0.001$ ), feeling ill (HNFI, $p<0.001$ ), pain killers (HNPK, $p<0.001$ ) and weight loss (HNWL, $p<0.001)$ scales for the cancer group with moderatesevere pain (Figure 2). In each case, the HNSCC patients with moderate-severe pain reported greater difficulties than those with mild or no pain. The group with mild pain presented scores that were significantly worse than the no pain group on the senses problems (HNSE, $p<0.001$ ) and less sexuality (HNSX, $p=0.018$ ) scales.

The intensity of pain was not correlated with the tumor location (Figure 3); however, the group with larynx tumors had more patients without pain $(p=0.02)$. Analyzing the tumor classification, the group with T1 tumors had more patients with no pain $(p<0.001)$, conversely, patients with T4 tumors indicated a greater intensity of pain $(p=0.003)$. The absence of lymph node involvement (N0) revealed a difference in the percentage of patients without pain $(p=0.039)$ (Figure 4).

\section{Discussion}

This is the first study to evaluate the pain severity among untreated HNSCC patients and its impact on QoL. We hypothesized that the intensity of pain in patients with untreated HNSCC may be significantly correlated with a poor QoL. Patients with an advanced-stage tumor showed higher impairment in functional status (physical, role and social functioning) and worse symptoms, which is in accordance with the results of earlier studies [19-21] and demonstrates the strong correlation between tumor stage and QoL. Patients with an early-stage tumor had less pain compared with those who had an advanced-stage tumor. Regarding tumor site, although more patients with a tumor in the oral cavity indicated that they had moderate to severe pain, this difference was not significant and is difficult to compare with prior results because of the lack of earlier studies regarding the impact of pain intensity in pretreatment HNSCC patients.

The HNSCC patients with moderate to severe pain reported higher levels of interference on all of the functioning scales, the global QoL and the 4 symptoms (fatigue, pain, appetite loss and financial difficulties) on the EORTC QLQ-C30 scales, whereas patients without pain indicated better results on those scales. Thus, increasing pain is 


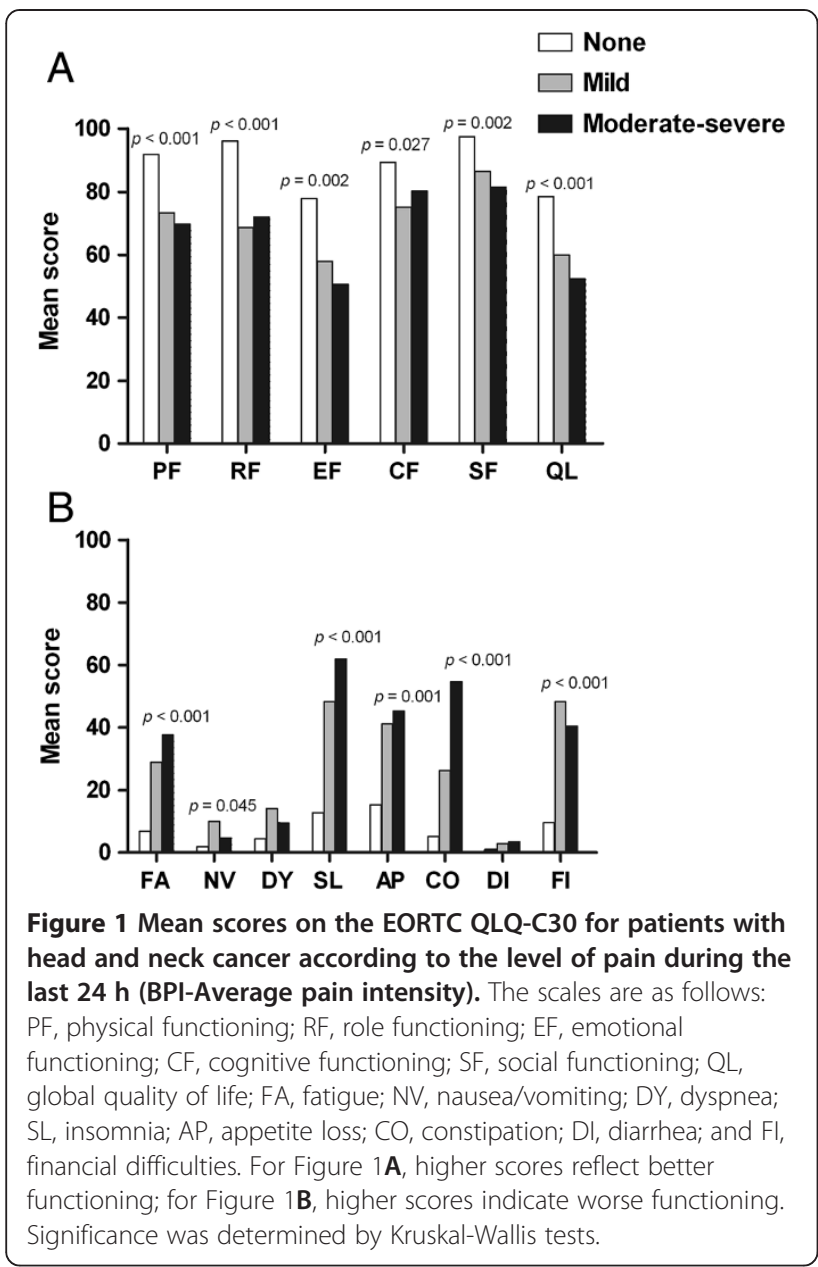

related to a reduced quality of life and increased symptoms. We found similar results with the EORTC QLQH\&N35 because the 11-symptom scales revealed the worst scores (indicating a high level of problems) for patients with moderate to severe pain.

In our study, although $66.9 \%$ of all patients reported that they had used analgesic medication for pain control, the number of patients with pain (59\%) remained high, similar to what was found in an earlier study [22]. While we did not evaluate the analgesic efficacy or regimens, the persistence of pain may reflect the possibility that it is difficult for patients to report their symptoms to a physician or may suggest that the patients' medication may not be adequately effective. Patients with head and neck, gastrointestinal and thoracic malignancies are more likely to experience severe pain compared with patients with other tumors $(52.6 \%, 33.9 \%$ and $30.5 \%$, respectively) [23]. Another study has shown that $58 \%$ of HNC patients felt that it was necessary to fill in the QoL questionnaire before their visit because this would help them to describe their symptoms to their doctors [24].

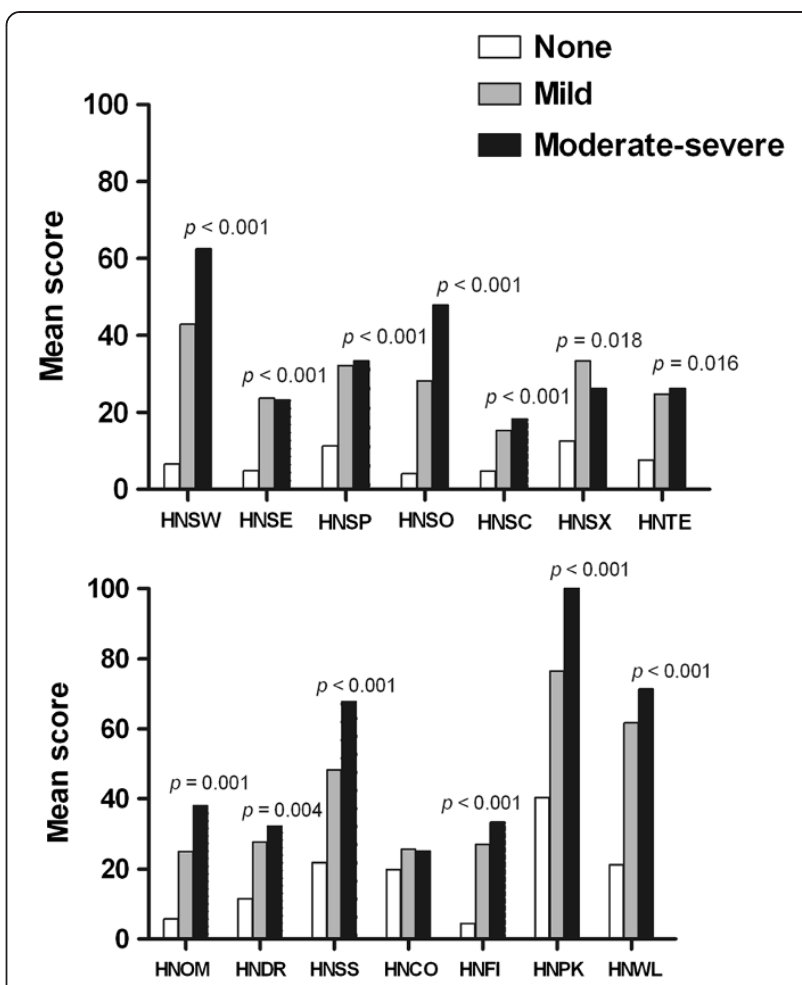

Figure 2 Mean scores on the EORTC QLQ-H\&N35 for patients with head and neck cancer according to the level of pain during the last $\mathbf{2 4} \mathrm{h}$ (BPI-average pain intensity). The scales are as follows: HNSW, swallowing; HNSE, senses; HNSP, speech; HNSO, social eating; HNSC, social contact; HNSX, sexuality; HNTE, teeth; HNOM, opening mouth; HNDR, dry mouth; HNSS, sticky saliva, HNCO, coughing; HNFI, felt ill; HNPK, pain killers; and HNWL, weight loss. Higher scores indicate poorer functioning. Significance was determined by Kruskal-Wallis tests.

Normally, cancer pain is classified into three categories: pain caused by tumor growth, pain caused by treatment, and pain unrelated to cancer [25]. Therefore, we excluded pain caused by treatment because the evaluation of our patients was performed before of any type of cancer treatment. Tumor growth may cause pain by compressing and invading surrounding tissues, including muscles, bones,

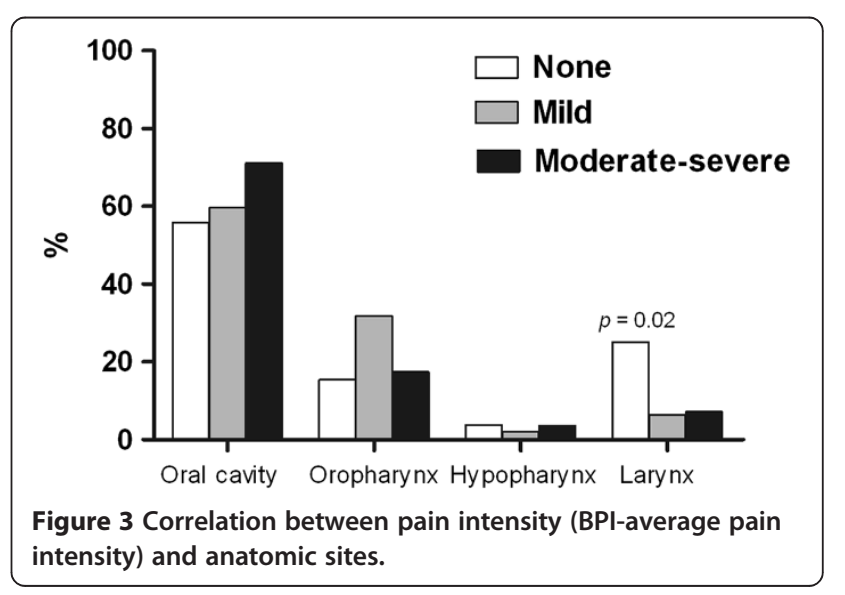




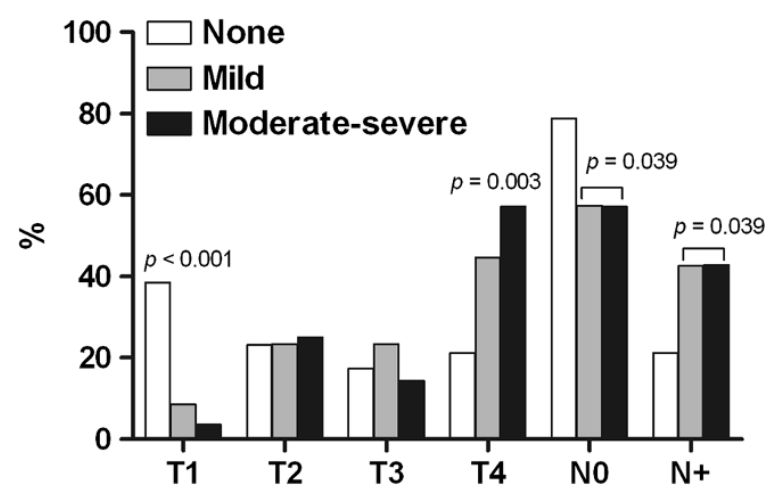

Figure 4 Correlation between pain intensity (BPI-average pain intensity) and TN stage. T: tumor size; N: lymph node involvement.

and peripheral nerves. Additionally, the head and neck have a rich blood supply and a large numbers of nerves that may affect tumor growth and pain $[25,26]$.

A potential limitation of our study might be that we chose to use the BPI average pain intensity item as the pain intensity criterion, the study was performed with moderate sample, and patients' recruitment was from one center. However, evaluating the level of pain experienced most frequently is more important for assessing pain's interference than evaluating shorter periods with the highest/lowest pain intensities. Additionally, this criterion is in accordance with other studies [27-30], and the BPI is recommended by the European Association of Palliative Care as a pain assessment tool in clinical studies [31]. As in prior studies, each of the questionnaire scales demonstrated acceptable reliability, with the exception of the cognitive functioning scale, which has been problematic $[9,14,32-35]$.

Although head and neck cancer has the highest prevalence of pain [7], clinical health care professionals focus on the preparation for surgery and issues of the immediate post-operative period, and the management of symptoms is neglected [36]. Furthermore, palliative care is initiated only for end-stage cancer patients, and the mean time from the initiation of palliative care to death is 21.9 days in head and neck cancer patients, suggesting that incurable patients may be referred to palliative care institutions too late. The majority of patients (85\%) admitted to palliative care had inadequate pain control prior to admission [37]. Therefore, an evaluation of patients before the initiation of anti-cancer therapy is important because most studies have focused on the analysis of pain during or after treatment.

\section{Conclusions}

Assessing the quality of life and symptoms before therapy can direct attention to the most important symptom, such as pain, and thus, appropriate interventions can improve QoL outcomes and the response to treatment.

\section{Abbreviations}

QoL: Quality of life; HNC: Head and neck cancer; HNSCC: Head and neck squamous cell carcinoma; EORTC QLQ-C30: European Organization for Research and Treatment of Cancer Quality of Life Questionnaire Core-30; QLQ-H\&N35: Quality of Life Questionnaire Head and Neck Cancer Module; BPI: Brief Pain Inventory; SPSS: Statistical Package for the Social Sciences: T: Tumor size; N: Lymph node involvement; PF: Physical functioning; RF: Role functioning; EF: Emotional functioning; CF: Cognitive functioning; SF: Social functioning; QL: Global quality of life; FA: Fatigue; NV: Nausea/vomiting; DY: Dyspnea; SL: Insomnia; AP: Appetite loss; CO: Constipation; DI: Diarrhea; FI: Financial difficulties; HNSW: Swallowing; HNSE: Senses; HNSP: Speech; HNSO: Social eating; HNSC: Social contact; HNSX: Sexuality; HNTE: Teeth; HNOM: Opening mouth; HNDR: Dry mouth; HNSS: Sticky saliva;

HNCO: Coughing; HNFI: Felt ill; HNPK: Pain killers; HNWL: Weight loss.

\section{Competing interests}

The authors declare that they have no competing interests.

\section{Authors' contributions}

KGO, SWZ, NSB, SAG: contributed to the conception and design of the study, analysis of data and critically read the manuscript. JRVP, AS, EDS, JL: collected data and critical revision. All contributing authors have no disclosures to make. All authors read and approved the final manuscript.

\section{Acknowledgments}

This study was supported by the following grants: CAPES, FAPES, INCT-IF/ REBRAFVIME and CNPq. The authors would like to thank the medical team of Santa Rita de Cassia Hospital-AFECC, Vitoria, ES, Brazil, for their assistance with the collection of the data.

\section{Author details}

${ }^{1}$ Department of Physiological Sciences, Health Sciences Center, Federal University of Espirito Santo, Vitória, Brazil. 'Department of Pathology, Health Sciences Center, Federal University of Espirito Santo, Vitória, Brazil. ${ }^{3}$ Head and Neck Division - Santa Rita de Cássia Hospital - AFECC, Vitória, Brazil.

Received: 30 April 2013 Accepted: 20 December 2013

Published: 24 January 2014

\section{References}

1. Parkin DM, Bray F, Ferlay J, Pisani P: Global cancer statistics, 2002. CA Cancer J Clin 2005, 55:74-108.

2. Dobrossy L: Epidemiology of head and neck cancer: magnitude of the problem. Cancer Metastasis Rev 2005, 24:9-17.

3. Viet CT, Schmidt BL: Biologic Mechanisms of Oral Cancer Pain and Implications for Clinical Therapy. J Dent Res 2012, 91:447-453.

4. Connelly ST, Schmidt BL: Evaluation of pain in patients with oral squamous cell carcinoma. J Pain 2004, 5:505-510.

5. Cuffari L, de Tesseroli SJT, Nemr K, Rapaport A: Pain complaint as the first symptom of oral cancer: a descriptive study. Oral Surg Oral Med Oral Pathol Oral Radiol Endod 2006, 102:56-61.

6. Epstein JB, Emerton S, Kolbinson DA, Le ND, Phillips N, Stevenson-Moore P, Osoba D: Quality of life and oral function following radiotherapy for head and neck cancer. Head Neck 1999, 21:1-11.

7. van den Beuken-van Everdingen MH, de Rijke JM, Kessels AG, Schouten HC, van Kleef M, Patijn J: Prevalence of pain in patients with cancer: a systematic review of the past 40 years. Ann Oncol 2007, 18:1437-1449.

8. Black B, Herr K, Fine P, Sanders S, Tang X, Bergen-Jackson K, Titler M, Forcucci $C$ : The relationships among pain, nonpain symptoms, and quality of life measures in older adults with cancer receiving hospice care. Pain Med 2011, 12:880-889.

9. Sherman CA, Simonton S, Adams DC, Vural E, Owens B, Hanna E: Assessing quality of life in patients with head and neck cancer. Arch Otolaryngol Head Neck Surg 2000, 126:459-467.

10. Ferrell BR, Dow KH, Grant M: Measurement of the quality of life in cancer survivors. Qual Life Res 1995, 4:523-531.

11. Cleeland CS, Ryan K: Pain assessment: global use of the Brief Pain Inventory. Ann Acad Med Singapore 1994, 23:129-138.

12. Ferreira KA, Teixeira MJ, Mendonza TR, Cleeland CS: Validation of brief pain inventory to Brazilian patients with pain. Support Care Cancer 2011, 19:505-511. 
13. Serlin RC, Mendoza TR, Nakamura Y, Edwards KR, Cleeland CS: When is câncer pain mild, moderate or severe? Grading pain severity by its interference with function. Pain 1995, 61:277-284

14. Aaronson NK, Ahmedzai S, Bergman B, Bullinger M, Cull A, Duez NJ, Filiberti A, Flechtner H, Fleishman SB, de Haes JC, Kaasa S, Klee M, Osoba D, Razavi D, Rofe PB, Schraub S, Sneeuw K, Sullivan M, Takeda F: The European Organization for Research and Treatment of Cancer QLQ-C30: a quality-of-life instrument for use in international clinical trials in oncology. J Natl Cancer Inst 1993, 85:365-376.

15. Vartanian JG, Carvalho AL, Furia CLB, de Castro Junior G, Rocha CN, Sinitcovisky IML, Toyota J, Kowalski ISG, Federico MHH, Kowalski LP: Questionnaires validated in the Brazilian population for evaluation of the Quality of Life in patients with head and neck cancer. Rev Bras Cir Cabeça Pescoço 2007, 36:108-115.

16. Bjordal K, de Graeff A, Fayers P, Hammerlid E, van Pottelsberghe C, Curran $D$, Ahlner-Elmqvist M, Maher EJ, Meyza JW, Brédart A, Söderholm AL, Arraras $\mathrm{JJ}$, Feine JS, Abendstein $\mathrm{H}$, Morton RP, Pignon T, Huguenin P, Bottomly A, Kaasa S: A 12 country field study of the EORTC QLQ-C30 (version 3.0) and the head and neck cancer specific module (EORTC QLQ-H\&N35) in head and neck patients. EORTC Quality of Life Group. Eur J Cancer 2000, 36:1796-1807.

17. Bjordal K, Hammerlid E, Ahlner-Elmqvist M, de Graeff A, Boysen M, Evensen JF, Biörklund A, de Leeuw JR, Fayers PM, Jannert M, Westin T, Kaasa S: Quality of life in head and neck cancer patients: validation of the European Organization for Research and Treatment of Cancer Quality of Life Questionnaire-H\&N35. J Clin Oncol 1999, 17:1008-1019.

18. Fayers PM, Aaronson NK, Bjordal K, Groenvold M, Curran D, Bottomley A: The EORTC QLQ-C30 Scoring Manual. Brussels: European Organization for Research and Treatment of Cancer; 2001.

19. Borggreven PA, Verdonck-de Leeuw IM, Muller MJ, Heiligers ML, de Bree R, Aaronson NK, Leemans CR: Quality of life and functional status in patients with cancer of the oral cavity and oropharynx: pretreatment values of a prospective study. Eur Arch Otorhinolaryngol 2007, 264:651-657.

20. Rogers SN, Lowe D, Fisher SE, Brown JS, Vaughan ED: Health-related quality of life and clinical function after primary surgery for oral cancer. Br J Oral Maxillofac Surg 2002, 40:11-18.

21. Hammerlid E, Bjordal K, Ahlner-Elmqvist M, Boysen M, Evensen JF, Biörklund A, Jannert M, Kaasa S, Sullivan M, Westin T: A prospective study of quality of life in head and neck cancer patients. Part I: at diagnosis. Laryngoscope 2001, 111:669-680

22. Shuman AG, Terrell JE, Light E, Wolf GT, Bradford CR, Chepeha D, Jiang Y, McLean S, Ghanem TA, Duffy SA: Predictors of Pain Among Patients with Head and Neck Cancer. Arch Otolaryngol Head Neck Surg 2012 138:1147-1154.

23. Isaac T, Stuver SO, Davis RB, Block S, Weeks JC, Berry DL, Weingart SN: Incidence of severe pain in newly diagnosed ambulatory patients with stage IV cancer. Pain Res Manag 2012, 17:347-352.

24. Mehanna HM, Morton RP: Patients' views on the utility of quality of life questionnaires in head and neck cancer: a randomised trial. Clin Otolaryngol 2006, 31:310-316

25. Benoliel R, Epstein J, Eliav E, Jurevic R, Elad S: Orofacial pain in cancer: part I. Mechanisms. J Dent Res 2007, 86:491-505.

26. Vecht CJ, Hoff AM, Kansen PJ, de Boer MF, Bosch DA: Types and causes of pain in cancer of the head and neck. Cancer 1992, 70:178-184.

27. Skljarevski V, Desaiah D, Liu-Seifert H, Zhang Q, Chappell AS, Detke MJ, lyengar S, Atkinson JH, Backonja M: Efficacy and safety of duloxetine in patients with chronic low back pain. Spine (Phila Pa 1976) 2010, 35:E578-E585.

28. Hølen JC, Lydersen S, Klepstad P, Loge JH, Kaasa S: The Brief Pain Inventory: pain's interference with functions is different in cancer pain compared with noncancer chronic pain. Clin J Pain 2008, 24:219-225.

29. Fredheim OM, Kaasa S, Dale O, Klepstad P, Landrø NI, Borchgrevink PC Opioid switching from oral slow release morphine to oral methadone may improve pain control in chronic non-malignant pain: a nine-month follow-up study. Palliat Med 2006, 20:35-41.

30. Klepstad P, Borchgrevink PC, Dale O, Zahlsen K, Aamo T, Fayers P, Fougner $B$, Kaasa S: Routine drug monitoring of serum concentrations of morphine, morphine- 3-glucuronide and morphine- 6 glucuronide do not predict clinical observations in cancer patients. Palliat Med 2003, 17:679-687
31. Caraceni A, Cherny N, Fainsinger R, Kaasa S, Poulain P, Radbruch L, de Conno F: Pain measurement tools and methods in clinical research in palliative care: recommendations of an expert working group of The European Association of Palliative Care. J Pain Symptom Manage 2002, 23:239-255

32. Chaukar DA, Das AK, Deshpande MS, Pai PS, Pathak KA, Chaturvedi P, Kakade AC, Hawaldar RW, D'Cruz AK: Quality of life of head and neck cancer patient: validation of the European organization for research and treatment of cancer QLQ-C30 and European organization for research and treatment of cancer QLQ-H\&N 35 in Indian patients. Indian J Cancer 2005, 42:178-184.

33. Wisloff F, Eika W, Hippe E, Hjorth M, Holmberg E, Kaasa S, Palva I, Westin J: Measurement of health-related quality of life in multiple myeloma. $\mathrm{Br} J$ Haematol 1996, 92:604-613.

34. Kaasa S, Bjordal K, Aaronson N, Moum T, Wist E, Hagen S, Kvikstad A: The EORTC Core Quality of Life Questionnaire (QLQ-C30): validity and reliability when analysed with patients treated with palliative radiotherapy. Eur J Cancer 1995, 31A:2260-2263.

35. Bjordal K, Kaasa S: Psychometric validation of the EORTC Core Quality of Life Questionnaire, 30-item version and a diagnosis-specific module for head and neck cancer patients. Acta Oncol 1992, 31:311-321.

36. Chen SC, Yu WP, Chu TL, Hung HC, Tsai MC, Liao CT: Prevalence and correlates of supportive care needs in oral cancer patients with and without anxiety during the diagnostic period. Cancer Nurs 2010, 33:280-289.

37. Lin YL, Lin IC, Liou JC: Symptom patterns of patients with head and neck cancer in a palliative care unit. J Palliat Med 2011, 14:556-559.

doi:10.1186/1471-2407-14-39

Cite this article as: Oliveira et al:: Influence of pain severity on the quality of life in patients with head and neck cancer before antineoplastic therapy. BMC Cancer 2014 14:39.

\section{Submit your next manuscript to BioMed Central and take full advantage of:}

- Convenient online submission

- Thorough peer review

- No space constraints or color figure charges

- Immediate publication on acceptance

- Inclusion in PubMed, CAS, Scopus and Google Scholar

- Research which is freely available for redistribution 